\title{
BMJ Open Database analysis of the risk factors of bisphosphonate-related osteonecrosis of the jaw in Hungarian patients
}

\author{
Edit Veszelyné Kotán, ${ }^{1}$ Tímea Bartha-Lieb, ${ }^{2}$ Zsolt Parisek, ${ }^{2}$ Attiláné Meskó, ${ }^{1}$ \\ Mihály Vaszilkó, ${ }^{3}$ Balázs Hankó ${ }^{1}$
}

To cite: Veszelyné Kotán E, Bartha-Lieb T, Parisek Z, et al. Database analysis of the risk factors of bisphosphonate-related osteonecrosis of the jaw in Hungarian patients. BMJ Open 2019;9:e025600. doi:10.1136/ bmjopen-2018-025600

- Prepublication history for this paper is available online. To view these files, please visit the journal online (http://dx.doi. org/10.1136/bmjopen-2018025600).

Received 23 July 2018

Revised 14 March 2019

Accepted 19 March 2019

D Check for updates

(c) Author(s) (or their employer(s)) 2019. Re-use permitted under CC BY-NC. No commercial re-use. See rights and permissions. Published by BMJ.

${ }^{1}$ University Pharmacy

Department of Pharmacy

Administration,

Semmelweis Egyetem

Gyogyszeresztudomanyi Kar,

Budapest, Hungary

${ }^{2}$ Department of Information

Technology, Allami Egeszsegugyi

Ellato Kozpont, Budapest,

Hungary

${ }^{3}$ Department of Oro-Maxillofacial Surgery and Stomatology, Semmelweis University, Budapest, Hungary

Correspondence to Dr Edit Veszelyné Kotán; eveszely@gmail.com

\section{ABSTRACT}

Objective Bisphosphonate-related osteonecrosis of the jaw (BRONJ) is a rare but serious side effect of bisphosphonates (BPs). Since this disease has no independent code in either of the diseases' or in the medical procedures' classifications, it is hard to estimate how many BP patients are affected.

Design A retrospective observational epidemiological registry-based study was carried out, using the data of the national service of Hungary on the incidence of BRONJ and related factors.

Setting A data analysis was performed, which is relevant for the whole Hungarian population from 2010 to 2014. The socioeconomic and medication data of 236207 BP patients were analysed, and a method was worked out to define BRONJ patients from the Hungarian BP population. Primary and secondary outcome measures The incidences of BRONJ were analysed according to genders and the types of the BP drugs administered. The marginal interdependence between the types of BP drugs, modes of administration and main indication was calculated.

Results 340 BP patients (0.1\%) developed BRONJ. The incidence of BRONJ in Hungary in the malignant indication of $\mathrm{BPs}$ is $0.9 \%$, and $0.1 \%$ in the non-malignant indication, and the OR to develop BRONJ was OR=9.7 (95\% Cl 7.8 to 12.1) between them. Although more women developed BRONJ, the proportion of men was significantly higher than that of women. Steroids increase the risk of jaw osteonecrosis, and differences were also found between the BP drugs.

Conclusions Oncology indicated, intravenously administered and steroid comedicated BP therapies pose a high risk of developing BRONJ in the Hungarian population.

\section{INTRODUCTION}

Bisphosphonate-related osteonecrosis of the jaw (BRONJ) was first mentioned in the literature by Marx in 2003 and it was defined as a new disease by Ruggiero in 2004. ${ }^{12}$ The first guideline of the American Association of Oral and Maxillofacial Surgeons on BRONJ was published in 2007. ${ }^{3}$ This position paper was updated in 2009 and 2014. ${ }^{45}$ As per definition, BRONJ is present when there is denuded bone in the maxillofacial region which persists for $>8$ weeks from the diagnosis and

\section{Strengths and limitations of this study}

- Bisphosphonate-related osteonecrosis of the jaw (BRONJ) is a rare but very serious side effect of bisphosphonates (BPs), but it is hard to estimate how many BP patients are affected.

- A research method is developed to find BRONJ patients in the BP population.

- Since there is no independent codes of disease or medical procedures for this disease, a selection bias can occur, which is the limitation of the study. The applied screening method narrows the number of potential BRONJ patients.

- The study was not registered in any databases of clinical studies.

- More studies are needed with a logistic regression model to find the interdependence of the analysed factors.

the patients have been treated with bisphosphonate (BP) despite no history of irradiation to the head and neck region. ${ }^{4}$ Since 2014 the disease group has been called medication-related ONJ (MRONJ), considering the antiresorptive and antiangiogenic drugs which potentially cause the disease. ${ }^{5}$

BRONJ is a characteristic side effect of BPs. ${ }^{6}$ The factors affecting the development of the necrosis are numerous. However, female gender and age seem to be risk factors by themselves. ${ }^{37}$ Potential risk factors include medical, local, demographical, genetic and usual risk factors (eg, tobacco use, obesity), as well as comorbidities (renal failure, anaemia, diabetes). Besides, it also poses a risk what kind of disease (malignant or non-malignant) is treated with BP. The potential, namely the drug type, the mode and the length of the administration of BP and the types of co-medications can also present a risk. ${ }^{4-12}$ Among comedications, corticosteroids, immunosuppressants, antioestrogens and chemotherapy can increase the risk of the development of BRONJ. ${ }^{13-18}$ 


\section{Aims of the study}

BRONJ has no independent code in the International Classification of Diseases (ICD) and related health problems, which makes it difficult to identify the patients who develop BRONJ (BRONJ patients). The aim of this work was to work out a method with which BRONJ patients can be chosen out of the patients treated with BPs $(B P$ patients) whether they have a malignant or a non-malignant disease and to analyse the incidence and the risk factors of this side effect in the Hungarian population. It is hypothesised that there is a higher risk for developing BRONJ of the administration of BPs used in the malignant than in the non-malignant indication.

\section{Ethics approval}

The patients' healthcare data (prescriptions' data, ICD codes and codes of medical procedures) for the analyses were available from the National Healthcare Services Center's (NHSC) database through a research contract. The NHSC collects and handles the data of the National Health Insurance Fund (NHIF) of Hungary as a basic task and, therefore no ethics approval was needed for this study. The patients' personal data were converted to identification number (IDs) and the aggregated medical data were used for the evaluation, which can be considered blinding. None of the patients can be identified in any ways for the members of the research group.

\section{METHOD}

\section{Study design and patients}

A retrospective observational epidemiological registry-based study was carried out. The incidences of BRONJ were analysed according to genders, and the types of the BP drugs. The marginal interdependence between the types of BP drugs, modes of administration and main indication was calculated.

\section{Patient and public involvement}

Patients and public were not involved in the design and conduct of the study.

\section{Database and data collection}

To obtain enough data for the analysis of this rare side effect, the study team decided to analyse the healthcare data of the Hungarian population. In Hungary, the NHIF is the only organisation to reimburse healthcare-related expenditures, including medicines and healthcare institutions, which gives a nationwide relevance for the analysis. To avoid the disturbing effect of the other drugs causing ONJ, the available data were collected from 1 January 2010 to 31 December 2014. Since the period of the screening covers the era of the BRONJ, this definition has been used throughout the manuscript. The selected time frame ensured that the earliest available data were analysed from the study start date, and the end date assures that only the effect of the BP drug group was analysed without the effect of other drugs which can cause
MRONJ. The data were handled by professional experts of data handling from the NHSC, and they are coauthors of this paper (TB-L and ZP). The database of the NHSC is a validated database with limited access for users. This database is the basis of the Hungarian reimbursement system. Since the data analysed were extracted from a validated database, a group of randomly selected patients were chosen for the validation based on their coded personal healthcare data and the prescribed medicines.

First, the prescription data of the BP type medicines under Anatomical Therapeutic Chemical (ATC Classification System) codes were collected as follows: M05BA-bisphosphonates and $\mathrm{M} 05 \mathrm{BB}$ - bisphosphonate combinations. The prescription data contain the ICD code, which stands for the main indication of the use of the medication. This screen resulted in the BP population of Hungary. BRONJ patients were selected from the BP population using the NHIF inpatient care database. The selected ICD and International Classification of Procedures in Medicine (ICPM and related health problems) codes are shown in figure 1 . In this study, the BP patients selected according to both ICD and ICPM codes were defined as BRONJ patients. Irradiation to the head and neck region was considered an exclusion criterion. The ICPM codes of the irradiations were defined from the inpatient and outpatient care ICPM database of Hungary. NHIF refers to the ICPM codes as a basis of reimbursement. The parameters in the BRONJ patients' group were analysed until the first ICD or ICPM code in connection with BRONJ appeared. The no BRONJ group consists of the patients chosen from the database according to the ATC code of the prescribed medicine and have not developed BRONJ during the study time period. In this group, these parameters were taken into consideration for the whole time period of the study.

The effect of BPs was analysed according to drug types (different types of BP drugs: alendronate, clodronate, ibandronate, pamidronate, risedronate and zoledronic acid) and main indications. Malignant (M) and non-malignant (NM) groups of indications were separated on the basis of the name, package and reimbursement technique of the dispensed BP drug. ${ }^{19}$ The BP medicines with an indication of advanced malignancies involving bone (eg, the skeletal events of breast cancer, prostate cancer or multiple myeloma or tumour-induced hypercalcaemia) were administered to $M$ patients, and $N M$ patients were treated with BPs for postmenopausal, male or glucocorticoid-induced osteoporosis or Paget's disease of the bone. The patients included were grouped into Oral and Intravenous groups according to the mode of administration of the BP. In the Oral group, patients took their BP medicines orally. In the Intravenous group, BP drugs were administered to the patients intravenously or both intravenously and orally because the risk of BRONJ with intravenous BPs can be 100-1000 times higher than the risk with oral BPs. ${ }^{5}$ In the case of patients taking oral BPs, a 182-day time shift was required between the first BP dispensing and the onset of the disease. ${ }^{23}$ No time shift 
METHOD: National Health InSURANCE Fund database analysis DISPENSED BP PRESCRIPTIONS FROM 1 JANUARY 2010 TO 31 DECEMBER 2014. ATC M05BA, M05BB EXCLUSION CRITERION: THERAPEUTIC IRRADIATION TO THE HEAD AND NECK REGION

236,207 BP PATIENTS

+ Time shift from dispensing Oral BP patients 182 days from the 1st dispensing ${ }^{[1]}$; No time shift in Intravenous BP Patients

ICD codes in connection
with BRONJ

[1] American Association of Oral and Maxillofacial Surgeons Position Paper on Bisphosphonate- related Osteonecrosis of the Jaws. Advisory Task Force on Bisphosphonate- related Osteonecrosis of the Jaws. J Oral Maxillofac Surg 65:369, 2007.

Figure 1 Method of the definition of the Hungarian BP and BRONJ population. This figure represents the method which has been worked out to identify BRONJ patients from the Hungarian BP population. The BP users were screened according to the ATC code of the prescribed medicine from 2010 to 2014. After the exclusion of the patients who were irradiated in the head and neck region, a dual screen of the BRONJ patients was applied. According to the definition of this study, the BRONJ patients group consists of those patients whose data contain both the ICD and the ICPM codes regarding BRONJ. ATC, Anatomical Therapeutic Chemical; BP, bisphosphonate; BRONJ, bisphosphonate-related osteonecrosis of the jaw; ICD, International Classification of Diseases; ICPM, International Classification of Procedures in Medicine.

was required in the case of intravenous BPs because these medicines might increase the risk of BRONJ right after the first administration.

In this study, therapy switch was defined when another BP drug type and/or the same drug in another route was administered to a predefined patient. The doses of the different drug types were made comparable by using a relative total dose (RTD). Defined daily dose of drugs were used to calculate days of therapy (DOTs) of the medications. Dividing the DOT amounts of the dispensed BP drugs for every patient with the days spent at risk in the study time period gives the amount of the RTD. The days spent at risk means the study time period for non-necrosis patients. For necrosis patients, it means the days spent

Table 1 Age and gender characteristics of the study population

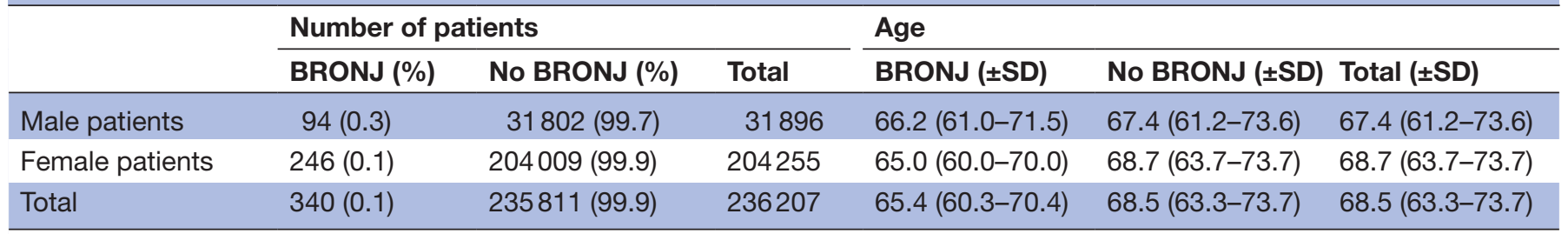

BRONJ, bisphosphonate-related osteonecrosis of the jaw. 
Table 2 Comparison of the main indications with administration routes and therapy switch of the bisphosphonates

\begin{tabular}{|c|c|c|c|c|}
\hline $\begin{array}{l}\text { Gender and main indication of } \\
\text { bisphosphonates* }\end{array}$ & BRONJ (\%) & No BRONJ (\%) & OR (95\% Cl) & $P$ value \\
\hline \multicolumn{5}{|l|}{ Male } \\
\hline Malignant & $68(0.9)$ & 7955 (99.1) & & \\
\hline Non-malignant & $28(0.1)$ & $24046(99.9)$ & $7.3(4.7$ to 11.4$)$ & $<0.0001$ \\
\hline \multicolumn{5}{|l|}{ Female } \\
\hline Malignant & $65(1.0)$ & $6465(99.0)$ & 10.9 (8.2 to 14.5$)$ & $<0.0001$ \\
\hline Non-malignant & $183(0.1)$ & $198220(99.9)$ & & \\
\hline \multicolumn{5}{|c|}{ Main indication and route of adminisrtation of bisphoshponates } \\
\hline \multicolumn{5}{|c|}{ Malignant and non-malignant disease } \\
\hline Intravenous & $4(0.7)$ & $604(99.3)$ & $3.2(0.2$ to 59.8$)$ & 0.43 \\
\hline Oral & $0(0.0)$ & $215(100.0)$ & & \\
\hline Total & $4(0.5)$ & $819(99.5)$ & & \\
\hline \multicolumn{5}{|l|}{ Malignant disease } \\
\hline Intravenous & $111(1.2)$ & 9409 (98.8) & 2.8 (1.7 to 4.5$)$ & 0.0001 \\
\hline Oral & $18(0.4)$ & $4210(99.6)$ & & \\
\hline Total & $129(0.9)$ & 13619 (99.1) & & \\
\hline \multicolumn{5}{|l|}{ Non-malignant disease } \\
\hline Intravenous & $67(0.1)$ & $51158(99.9)$ & 1.7 (1.3 to 2.2$)$ & 0.0004 \\
\hline Oral & $140(0.1)$ & 170271 (99.9) & & \\
\hline Total & $207(0.1)$ & 221429 (99.9) & & \\
\hline \multicolumn{5}{|l|}{ Total } \\
\hline Intravenous & $182(0.3)$ & $61171(99.7)$ & 3.3 (2.7 to 4.1$)$ & $<0.0001$ \\
\hline Oral & $158(0.1)$ & 174696 (99.9) & & \\
\hline Total & $340(0.1)$ & 235864 (99.9) & & \\
\hline
\end{tabular}

Therapy switch in the groups of oral and intravenous administrations

Oral bisphosphonates

\begin{tabular}{|c|c|c|c|c|}
\hline 1 type & $146(0.1)$ & 151390 (99.9) & 1.9 (1.0 to 3.4 ) & 0.04 \\
\hline$<1$ type & $12(0.1)$ & 23285 (99.9) & & \\
\hline Total & $158(0.1)$ & 174675 (99.9) & & \\
\hline \multicolumn{5}{|c|}{ Intravenous bisphosphonates } \\
\hline 1 type & $167(0.3)$ & $58102(99.7)$ & 0.9 (0.5 to 1.5$)$ & 0.69 \\
\hline$<1$ type & $15(0.5)$ & 3069 (99.5) & & \\
\hline Total & $182(0.3)$ & $61171(99.7)$ & & \\
\hline
\end{tabular}

Bold values are highlighting results.

*In malignant and non-malignant groups, patients taking bisphosphonates in both indications are present.

BRONJ, bisphosphonate-related osteonecrosis of the jaw.

between the beginning of the study and the first occurrence of an ICD or ICPM code related to the BRONJ.

The BP patients were selected from the study population to whom steroids (ATC group H02) were dispensed any number of times to analyse the effect of corticosteroid comedication. The risk increasing effect of the RTD of the $\mathrm{BPs}$ and the BP drug types were analysed in this group.

\section{Statistical analysis}

IBM SPSS Statistics V.20 programme was applied for the statistical analyses. Evaluation was performed by descriptive analysis, the kind of distribution of the data was checked by Kolgomorov-Smirnov test. For the comparisons of the proportions of the BRONJ caused by the different drug compounds, administration modes and main indications, Student's t-test was applied. Marginal interdependence between the variables (genders, drug compounds and so on) was calculated by counting marginal ORs and 95\% CIs. Mood's median test was used when the non-normally distributed data (RTDs of the drugs) were compared between patients' groups. The $\chi^{2}$ test was selected to analyse the 
difference between categorical variables. The level of significance was $\mathrm{p} \leq 0.05$.

\section{RESULTS}

Using the method developed for this study, the Hungarian BP population in the study time period amounted to 236207 patients. As a result of the two screening criteria, the BRONJ patients' number came up to $340(0.1 \%)$. The age and gender characteristics of the study population are presented in table 1, while the comparison of the basic indications and the routes of administration of BPs are presented in table 2 . Our results show significantly more BRONJ cases in male than in female BP patients, $\mathrm{p}<0.001$.

There was a significant difference between the BRONJ and the No BRONJ groups from the point of view of age, $\mathrm{p}<0.001$. In the BRONJ group, the proportion of female patients (F/M: $72.4 \% / 27.7 \%$ ) was significantly lower than in the whole study population (F/M: $86.5 \% / 13.5 \%)$, $\mathrm{p}<0.001$. The male patients developed BRONJ with a 2.5 times higher odds ( $95 \%$ CI 1.9 to $3.1, \mathrm{p}<0.001$ ) than female patients. The proportion of oncology patients was higher in male than in female patients (F/M: 3.2\%/25.2\%). With a multinomial $\chi^{2}$ test, this difference was significant, $\mathrm{p}<0.001 .72 .3 \%$ of male and $26.4 \%$ of female BRONJ patients used their BPs in malignant indications. A multinomial $\chi^{2}$ probe showed that the difference was also significant between males and females, $\mathrm{p}<0.001$.

The new BRONJ cases in the 5-year study time period numbered 133 in the $M$ indication of BPs, and 211 in the $N M$ group. These data also include the patients with combined indications of BPs. On the basis of these results, the incidences were $0.9 \%$ and $0.1 \%$, respectively. The BRONJ patients' proportion was significantly higher in the oncology BP group than that in the study population $(\mathrm{p}<0.001)$, and also than that of the non-malignant indication (OR=9.7, 95\% CI 7.8 to 10.1, $\mathrm{p}<0001)$. In the Intravenous $B P$ group, the proportion of BRONJ patients was significantly higher than that in the whole study population $(p<0.001)$. In the oral BP group of patients who took one drug type, the BRONJ patients' proportion was significantly higher than that in the total oral BP population $(p=0.04)$. Relatively more BRONJ patients treated with more types of $\mathrm{BP}$ drugs were found in the Intravenous BP patients' group, but in the Oral pantients' group the odds of patients who took one type of $\mathrm{BP}$ was higher than that of patients who were administered more BP drug types. These results are presented in table 2.

Table 3 presents the proportion of BRONJ patients in drug types with administration modes. According to the results of the multinomial $\chi^{2}$ test, the proportion of $B R O N J$ patients was significantly higher in the clodronate, oral ibandronate, pamidronate and zoledronic acid groups than those in the study population. In the alendronateand risedronate groups, the proportion of BRONJ patients was significantly lower than in the total population.

The mean RTDs of the dispensed BPs are presented in table 4 according to drug types.

The difference in the proportion of BRONJ cases was defined between each pair of drug types. Table 5 gives the $\mathrm{p}$ values and ORs. This shows whether a drug compound has a stronger effect on the development of BRONJ than another.

\section{Glucocorticoid comedication}

In the BP patients' group treated with glucocorticoids (steroid BP group; $\mathrm{n}=44784$ ), the proportion of BRONJ (80 patients, $0.2 \%$ ) was significantly higher than in the steroid non-taker BP group ( $\mathrm{n}=191423$, BRONJ: 260 patients, $0.1 \%)(\mathrm{p}=0.013), \mathrm{OR}=1.3$ (95\% CI 1.0 to $1.7, \mathrm{p}=0.03)$. In

\begin{tabular}{|c|c|c|c|c|c|}
\hline $\begin{array}{l}\text { Drug and } \\
\text { administration route }\end{array}$ & BRONJ (\%) & No BRONJ (\%) & Total & $P$ value & Necroses \\
\hline Clodronate oral & $23(6.8)$ & 4588 (1.9) & 4611 & $<0.001$ & More necroses \\
\hline $\begin{array}{l}\text { Clodronate } \\
\text { intravenous }\end{array}$ & $0(0.0)$ & $65(0.0)$ & 65 & 0.75 & Not significant \\
\hline Ibandronate oral & $29(8.5)$ & $11408(4.8)$ & 11437 & 0.003 & More necroses \\
\hline $\begin{array}{l}\text { Ibandronate } \\
\text { intravenous }\end{array}$ & 44 (12.9) & 35850 (15.2) & 35894 & 0.31 & Not significant \\
\hline $\begin{array}{l}\text { Pamidronate } \\
\text { intravenous }\end{array}$ & $11(3.2)$ & $1223(0.5)$ & 1234 & $<0.001$ & More necroses \\
\hline Alendronate oral & $133(39.1)$ & $142075(60.2)$ & 142208 & $<0.001$ & Fewer necroses \\
\hline Risedronate oral & $46(13.5)$ & 66451 (28.2) & 66497 & $<0.001$ & Fewer necroses \\
\hline $\begin{array}{l}\text { Zoledronic acid } \\
\text { intravenous }\end{array}$ & $142(41.8)$ & 27117 (11.5) & 27259 & $<0.001$ & More necroses \\
\hline Total & $340(100.0)$ & 235867 (100.0) & 236207 & NA & Basis of comparison \\
\hline
\end{tabular}

Whether the given drug compound and administration route result in more or fewer necroses than it was found in the whole study population.

BRONJ, bisphosphonate-related osteonecrosis of the jaw. 


\begin{tabular}{|c|c|c|c|c|}
\hline $\begin{array}{l}\text { Relative total } \\
\text { doses }\end{array}$ & Mean & SD & SE mean & $P$ value \\
\hline \multicolumn{5}{|l|}{ Clodronate oral } \\
\hline BRONJ & 0.055 & 0.32 & 0.02 & \multirow[t]{2}{*}{0.007} \\
\hline No BRONJ & 0.008 & 0.48 & 0.00 & \\
\hline \multicolumn{5}{|c|}{ Clodronate intravenous } \\
\hline BRONJ & 0.000 & 0.00 & 0.00 & \multirow[t]{2}{*}{0.80} \\
\hline No BRONJ & 0.000 & 0.00 & 0.00 & \\
\hline \multicolumn{5}{|c|}{ Ibandronate oral } \\
\hline BRONJ & 0.137 & 1.34 & 0.07 & \multirow[t]{2}{*}{0.15} \\
\hline No BRONJ & 0.033 & 0.95 & 0.00 & \\
\hline \multicolumn{5}{|c|}{ Ibandronate intravenous } \\
\hline BRONJ & 0.089 & 0.39 & 0.02 & \multirow[t]{2}{*}{0.69} \\
\hline No BRONJ & 0.080 & 0.45 & 0.00 & \\
\hline \multicolumn{5}{|c|}{ Pamidronate intravenous } \\
\hline BRONJ & 0.026 & 0.17 & 0.01 & \multirow[t]{2}{*}{0.009} \\
\hline No BRONJ & 0.002 & 0.03 & 0.00 & \\
\hline \multicolumn{5}{|c|}{ Alendronate oral } \\
\hline BRONJ & 0.474 & 1.17 & 0.06 & \multirow[t]{2}{*}{0.79} \\
\hline No BRONJ & 0.434 & 2.80 & 0.01 & \\
\hline \multicolumn{5}{|c|}{ Risedronate oral } \\
\hline BRONJ & 0.106 & 0.48 & 0.03 & \multirow[t]{2}{*}{0.46} \\
\hline No BRONJ & 0.171 & 1.62 & 0.00 & \\
\hline \multicolumn{5}{|c|}{ Zoledronate intravenous } \\
\hline BRONJ & 0.338 & 0.83 & 0.05 & \multirow[t]{2}{*}{$<0.001$} \\
\hline No BRONJ & 0.065 & 0.65 & 0.00 & \\
\hline
\end{tabular}

Bold values are statistically significant.

The mean relative total doses of the drugs in the BRONJ and No $B R O N J$ patients' groups and the differences that were found. BRONJ, bisphosphonate-related osteonecrosis of the jaw.

the group of steroid BP patients, there were two BRONJ cases among the patients treated with BPs both in $M$ and in $N M$ indications $(\mathrm{n}=283$, BRONJ $0.71 \%, \mathrm{p}=0.04)$, and in $M$ indications there were 37 BRONJ cases out of 2839 patients $(1.3 \%, \mathrm{p}<0.001)$, significantly higher than those of the total steroid BP population. In the $N M$ group, $41 \mathrm{BRONJ}$ cases out of 41662 steroid BP patients occurred $(0.1 \%)$, significantly fewer than in the total steroid BP group $(\mathrm{p}=0.0016)$. There is a 12.3 OR $(95 \%$ CI 8.0 to $19.0, \mathrm{p}<0001)$ between the $M$ and NM steroid patients' groups to develop BRONJ. There is no significant difference between the group of both indications and the $M$ BP groups $(\mathrm{p}=0.39)$, but the result of the $M \mathrm{BP}$ group is significantly higher than that of the $N M$ indication group $(\mathrm{p}<0.001)$.

Carrying out a Mood's median test, the median RTD of BPs in the patients who took steroids with BPs (median RTD: 0.481 [0.2-0.9]) does not differ from that of those patients who did not take steroids (median RTD: 0.473
[0.2-1.0]). Steroid BRONJpatients' ( $\mathrm{n}=80$, median RTD of BPs: 0.771 [0.5-1.1]) median total RTD of BPs was significantly higher than that of the No BRONJ steroid patients $(n=44704$, the median RTD of BPs was 0.481 [0.2-0.9]) $(p<0.001)$. The RTD of BP is higher in the steroid BRONJ group in the case of oral clodronate, parenteral ibandronate, pamidronate and zoledronic acid. This difference is only significant in the zoledronic acid BP group, $\mathrm{p}<0.001$. The RTD of BP is lower in the steroid BP group of patients in the oral ibandronate, alendronate and risedronate BP groups, in which only risendronate is significant: $\mathrm{p}=0.001$.

\section{DISCUSSION}

BRONJ has not been studied in the Hungarian population yet. The higher number of BRONJ in male patients is attributed to the fact that there is a higher proportion of male than female oncology patients in the Hungarian $\mathrm{BP}$ population. The number of female BRONJ patients was higher because women make up more of the total BP population (postmenopausal osteoporosis). According to the results, the proportion of male BRONJ patients was higher even in the NM indication of BPs than that of female BRONJ patients. The underlying cause was presumably the increasing use of intravenous BPs because of non-adherence and the presence of other (eg, local) risk factors. Since the database of the Hungarian NHIF provides the medical and the main demographical data of the patients, but the local, genetic and usual risk factors are not included, these factors were not accessible for the analyses.

The results of the studies on the incidence of BRONJ cover a wide range. The results of this study are comparable to the international results of malignant $(0.9 \% / 0.8 \%-11 \%)$ and also non-malignant indications of BPs $(0.1 \% / 0.001 \%-0.7 \%) .{ }^{20-38}$ The number of patients with osteoporosis in Hungary is increasing. These patients' adherence is very low and a relatively high number of patients receive no adequate treatment. ${ }^{39}$ The latter results in the under treatment of these patients, but side effects or medical combinations which increase the risks of side effects might occur in the long term.

Switching therapy (using more than one type of BP drug or using the same drug in another administration route) in a group of a single drug type usually increases the risk of side effects. From the references, it can be concluded that in the case of intravenous BPs, the BP type and the length of therapy have a stronger effect than the switch itself. $^{3133}$ In this study population, more BRONJ occured in the patients' group treated with one type of oral BPs than in the switched group, and there were more BRONJ cases in the switched intravenous BP group than in the non-switched group. Oral BPs are mainly used in non-malignant indications, and the length of therapy might have a stronger effect on the risk of BRONJ than the switching therapy. In oncology, clodronate might be used to increase the effect of other intravenous BPs, or the less effective BP might be changed for a more effective one to 
Table 5 Difference of proportion of BRONJ in the drug groups (on the basis of the results of table 3)

\begin{tabular}{|c|c|c|c|c|c|c|c|}
\hline Drug groups & $\begin{array}{l}\text { CLO } \\
\text { intravenous } \\
(95 \% \mathrm{Cl}) \\
\end{array}$ & $\begin{array}{l}\text { IBA oral } \\
(95 \% \mathrm{CI})\end{array}$ & $\begin{array}{l}\text { IBA } \\
\text { intravenous } \\
(95 \% \mathrm{Cl})\end{array}$ & PAM $(95 \%$ Cl) & ALE $(95 \% \mathrm{Cl})$ & RIS (95\% CI) & ZOL $(95 \% \mathrm{Cl})$ \\
\hline $\begin{array}{l}\text { CLO } \\
\text { intravenous* }\end{array}$ & & $\begin{array}{l}\text { OR: } 0.3 \\
(0.0 \text { to } 5.6) \\
p=0.45\end{array}$ & $\begin{array}{l}\text { OR: } 0.2 \\
(0.0 \text { to } 2.7), \\
p=0.20\end{array}$ & $\begin{array}{l}\text { OR: } 1.2 \\
(0.1 \text { to } 21.1) \\
p=0.89\end{array}$ & $\begin{array}{l}\text { OR: } 0.1 \\
(0.0 \text { to } 2.0) \\
p=0.14\end{array}$ & $\begin{array}{l}\text { OR: } 0.1 \\
(0.1 \text { to } 1.5), \\
p=0.09\end{array}$ & $\begin{array}{l}\text { OR: } 0.7 \\
(0.0 \text { to } 11.2), \\
p=0.79\end{array}$ \\
\hline IBA oral & & & $\begin{array}{l}\text { OR: } 0.5 \\
(0.3 \text { to } 0.8) \\
p=0.002\end{array}$ & $\begin{array}{l}\text { OR: } 3.5 \\
(1.7 \text { to } \\
7.1), p<0.001\end{array}$ & $\begin{array}{l}\text { OR: } 0.4 \\
(0.2 \text { to } \\
0.6), p<0.001\end{array}$ & $\begin{array}{l}\text { OR: } 0.3 \\
(0.2 \text { to } \\
0.4), p<0.001\end{array}$ & $\begin{array}{l}\text { OR: } 2.1 \\
(1.4 \text { to } \\
3.1), p<0.001\end{array}$ \\
\hline IBA intravenous & & & & $\begin{array}{l}\text { OR: } 7.3 \\
\text { (3.7 to } \\
14.2), p<0.001\end{array}$ & $\begin{array}{l}\text { OR: } 0.8 \\
(0.5 \text { to } 1.1), \\
p=0.12\end{array}$ & $\begin{array}{l}\text { OR: } 0.6 \\
(0.4 \text { to } 0.9) \\
p=0.006\end{array}$ & $\begin{array}{l}\text { OR: } 4.3 \\
(3.0 \text { to } \\
6.0), p<0.001\end{array}$ \\
\hline ALE & & & & & & $\begin{array}{l}\text { OR: } 0.7 \\
(0.5 \text { to } 1.0) \\
p=0.08\end{array}$ & $\begin{array}{l}\text { OR: } 5.6 \\
(4.4 \text { to } \\
7.1), p<0.001\end{array}$ \\
\hline RIS & & & & & & & $\begin{array}{l}\text { OR: } 7.6 \\
(5.4 \text { to } \\
10.6), p<0.001\end{array}$ \\
\hline
\end{tabular}

Bold values are statistically significant.

This table shows whether a drug has a stronger effect to develop BRONJ than the other one.

*In the case of intravenous CLO, 0.5 cases were added to each patients' number in the equation to be able to count ORs.

ALE, alendronate; BRONJ, bisphosphonate-related osteonecrosis of the jaw; CLO, clodronate; IBA, ibandronate; PAM, pamidronate;

$\mathrm{RIS}$, risedronate; ZOL, zoledronic acid.

improve patient status in the short term. Non-aminoBP clodronate has no proven risk-increasing effect, but the cumulative effect of BPs cannot be excluded..$^{40}$

In contrast to previous studies, our study illustrates that there were more BRONJ patients in the group of alendronate and ibandronate patients during the study period in Hungary. BRONJ in the weekly administered alendronate patients is $0.01 \%-0.04 \% .^{23}$ This ratio was $0.09 \%$ in this study, which might be the result of the status of the Hungarian patients with osteoporosis: the number on alendronate is very high, but adherence is inadequate. ${ }^{42}$ In the references, $0.05 \%-0.07 \%$ of the long-term ibandronate users develop BRONJ, which is lower than our result of $0.12 \%$ (intravenous ibandronate) and $0.25 \%$ (oral ibandronate) in the case of the non-malignant ibandronate users. ${ }^{43}{ }^{44}$ A lower incidence of BRONJ (0.89\%) was found in the present study among the patients who were administered pamidronate than in another study which showed $4 \% .{ }^{33}$ The administration of pamidronate is gradually being replaced by the increasing use of ibandronate and zoledronic acid.

Similar to previous studies, our study confirms that ibandronate is considered to be less potent from the point of view of BRONJ than zoledronic acid in the malignant indication. ${ }^{45}{ }^{46}$ Zoledronic acid in NM indication causes BRONJ in $0.02 \%$, while the result of the present study was
$0.22 \% .{ }^{47}$ According to the results of other studies, BRONJ is present in approximately $0.7 \%-10 \%$ of zoledronic acid oncology patients. ${ }^{80}$ A lower percentage $(1.2 \%)$ was found in the Hungarian BP population.

Intravenous BPs and aminoBPs have a stronger effect on developing BRONJ than oral and non-aminoBPs, according to the order of potency. There are fewer BRONJ cases in clodronate, risedronate and oral ibandronate than alendronate, which is the result of the potency and the widespread use of alendronate. ${ }^{47} 48$ Alendronate shows a lower risk than intravenous BPs, while intravenous ibandronate has a lower risk than pamidronate and zoledronic acid. ${ }^{849}$

There is a higher risk of BRONJ in a given BP drug group with a higher total dose in both main indications of BPs. ${ }^{8} 314650$ In NM indications, the total length of the therapy has a stronger effect on the development of the side effects than the total dose. ${ }^{46}$ In this study, BRONJ patients were administered a significantly higher total dose of BP than no BRONJpatients in the oral clodronate, the pamidronate and the zoledronic acid groups. In ibandronate and alendronate patients, the total dose of $\mathrm{BP}$ in BRONJ patients was not significantly higher. In risedronate patients, BRONJ patients had a lower total dose, but not significantly. In this case, we hypothesise the presence of other non-drug-dependent risk factors. 
Glucocorticoids increase the risk of BRONJ. ${ }^{50} 51$ The necrosis might occur earlier, it is more severe and reacts slower to the discarding of $\mathrm{BP}^{52}$ In steroid BP patients, there is a significantly higher proportion of BRONJ patients than in the whole BP population. There is a higher risk of developing BRONJ when a higher dose of $\mathrm{BP}$ is administered to a patient with steroid comedication, and there are differences between the BP drugs. Alendronate and risedronate $\mathrm{BP}$ dose is higher in the steroid No $B R O N J$ group than in the steroid BRONJ group, and the zoledronic acid dose is lower, respectively. Alendronate and risedronate cumulative doses possibly have a weaker effect on BRONJ than the steroid comedication, and in the case of zoledronic acid, this effect is reversed.

\section{Limitations}

The database which this research group could access did not include dose, prescription or medication data from the period before 2010. From the risk factors of BRONJ, cumulative doses and the length of the BP therapy were not analysable, and the exposure bias has not been considered in the absence of relevant data. This study was not registered to any databases of clinical trials.

Since there are no independent ICD and ICPM codes of this disease, a selection bias can occur, which is the limitation of the study. The applied screening method narrows the number of potential BRONJ patients.

The effect of the BP drugs were analysed without considering the effect of other risk factors and the interdependence of the analysed risk factors. The single effect of the drugs, the main indication and the administration forms were compared. To analyse the combined effect of these factors, the application of a logistic regression model would be necessary.

\section{CONCLUSIONS}

These data are the first to have defined the incidence data of BRONJ in the Hungarian BP population according to the main indications of BPs and routes of administration. Our results show differences between BP drugs in their potential to cause BRONJ independently of their doses. Duality was typical in gender, main indication and also in the mode of administration of BPs. Male, oncology and intravenous BP patients were at a higher risk of developing BRONJ, but the significantly higher number of the opposite population of these groups resulted in a higher number of BRONJ in the groups of female patients, osteoporosis and oral BP patients. In the Hungarian BP population, the risk increasing main factors of BRONJ were corticosteroid comedication and BPs with malignant indication. More studies are needed to find the interdependence of the analysed factors.

Contributors The revised manuscript has been read and approved by all authors. All persons listed as authors have contributed to preparing the manuscript, and no persons other than the authors listed have contributed significantly to the preparation of the revision. $\mathrm{BH}$ and MV designed, directed and supervised the project with the help of ZP. TB-L and ZP collected the data from the database of the National Healthcare Services Center of Hungary. The data collection was supported by EVK. AM performed the statistical analyses. The data interpretation was performed by TB-L, ZP and EVK with the help of AM. All authors discussed the results, and EVK wrote the manuscript with input from all authors. BH and MV revised the manuscript.

Funding The authors have not declared a specific grant for this research from any funding agency in the public, commercial or not-for-profit sectors.

Competing interests None declared.

Patient consent for publication Not required.

Provenance and peer review Not commissioned; externally peer reviewed.

Data sharing statement The authors are not able to provide the full study dataset, since the database is the property of the National Healthcare Services Center of Hungary, and these data are not free for public application. The raw data are not public, the authors had an access to this database based on a contract between the researcher (Semmelweis University, Budapest, Hungary) and the NHSC.

Open access This is an open access article distributed in accordance with the Creative Commons Attribution Non Commercial (CC BY-NC 4.0) license, which permits others to distribute, remix, adapt, build upon this work non-commercially, and license their derivative works on different terms, provided the original work is properly cited, appropriate credit is given, any changes made indicated, and the use is non-commercial. See: http://creativecommons.org/licenses/by-nc/4.0/.

\section{REFERENCES}

1. Marx RE. Pamidronate (Aredia) and zoledronate (Zometa) induced avascular necrosis of the jaws: a growing epidemic. J Oral Maxillofac Surg 2003;61:1115-7.

2. Ruggiero SL, Mehrotra B, Rosenberg TJ, et al. Osteonecrosis of the jaws associated with the use of bisphosphonates: a review of 63 cases. J Oral Maxillofac Surg 2004;62:527-34.

3. American Association of Oral and Maxillofacial Surgeons Position Paper on Bisphosphonate- related Osteonecrosis of the Jaws. Advisory Task Force on Bisphosphonate- related Osteonecrosis of the Jaws. J Oral Maxillofac Surg 2007;65:369-76.

4. Ruggiero SL, Dodson TB, Assael LA, et al. American Association of Oral and Maxillofacial Surgeons. American Association of Oral and Maxillofacial Surgeons position paper on bisphpsphonate-related osteonecrosis of the jaws - 2009 update. J Oral Maxillofac Surg 2009;67:2-12.

5. Ruggiero SL, Dodson TB, Fantasia J, et al. American Association of Oral and Maxillofacial Surgeons position paper on medicationrelated osteonecrosis of the jaw--2014 update. J Oral Maxillofac Surg 2014;72:1938-56.

6. Gyires K, Zs F. Farmakológia Medicina, 2007

7. Vaszilkó M. Osteonecrosis of the jaws: Real and unreal scares LAM KID. 2011:1;5-14.

8. Vahtsevanos K, Kyrgidis A, Verrou E, et al. Longitudinal cohort study of risk factors in cancer patients of bisphosphonate-related osteonecrosis of the jaw. J Clin Oncol 2009;27:5356-62.

9. Lo JC, O'Ryan FS, Gordon NP, et al. Predicting Risk of Osteonecrosis of the Jaw with Oral Bisphosphonate Exposure (PROBE) Investigators. Prevalence of osteonecrosis of the jaw in patients with oral bisphosphonate exposure. J Oral Maxillofac Surg 2010;68:243-53.

10. Henry DH, Costa L, Goldwasser F, et al. Randomized, double-blind study of denosumab versus zoledronic acid in the treatment of bone metastases in patients with advanced cancer (excluding breast and prostate cancer) or multiple myeloma. J Clin Oncol 2011;29:1125-32.

11. Yamazaki T, Yamori M, Ishizaki T, et al. Increased incidence of osteonecrosis of the jaw after tooth extraction in patients treated with bisphosphonates: a cohort study. Int J Oral Maxillofac Surg 2012;41:1397-403.

12. Tsao C, Darby I, Ebeling PR, et al. Oral health risk factors for bisphosphonate-associated jaw osteonecrosis. J Oral Maxillofac Surg 2013;71:1360-6.

13. Medicines and Healthcare products Regulatory Agency: Bevacizumab and Sunitinib: risk of osteonecrosis of the jaw. Drug Safety Update. 2011;4. https://www.gov.uk/drug-safety-update/ bevacizumab-and-sunitinib-risk-of-osteonecrosis-of-the-jaw

14. Guarneri V, Miles D, Robert N, et al. Bevacizumab and osteonecrosis of the jaw: incidence and association with bisphosphonate therapy in three large prospective trials in advanced breast cancer. Breast Cancer Res Treat 2010;122:181-8. 
15. Beuselinck B, Wolter P, Karadimou A, et al. Concomitant oral tyrosine kinase inhibitors and bisphosphonates in advanced renal cell carcinoma with bone metastases. Br J Cancer 2012;107:1665-71.

16. Smidt-Hansen T, Folkmar TB, Fode K, et al. Combination of zoledronic Acid and targeted therapy is active but may induce osteonecrosis of the jaw in patients with metastatic renal cell carcinoma. J Oral Maxillofac Surg 2013;71:1532-40.

17. Saad F, Brown JE, Van Poznak C, et al. Incidence, risk factors, and outcomes of osteonecrosis of the jaw: integrated analysis from three blinded active-controlled phase III trials in cancer patients with bone metastases. Ann Oncol 2012;23:1341-7.

18. Vaszilko M, Kovacs E, Restar L, et al. Potential significance of antiestrogen therapy in the development of bisphosphonate related osteonecrosis of the jaw. $J$ Craniomaxillofac Surg 2014:42:1932-6.

19. Veszelyné KE, Á M. Therapeutic practice of bisphosphonate use and related pharmaceutical issues I-II Acta Pharmaceutica Hungarica. 2016;86:13-22.

20. Ruggiero SL, Mehrotra B. Bisphosphonate-related osteonecrosis of the jaw: diagnosis, prevention, and management. Annu Rev Med 2009;60:85-96.

21. Bilezikian JP. Osteonecrosis of the jaw-do bisphosphonates pose a risk? N Engl J Med 2006;355:2278-81.

22. Boonyapakorn T, Schirmer I, Reichart PA, et al. Bisphosphonateinduced osteonecrosis of the jaws: prospective study of 80 patients with multiple myeloma and other malignancies. Oral Oncol 2008;44:857-69.

23. Mavrokokki T, Cheng A, Stein B, et al. Nature and frequency of bisphosphonate-associated osteonecrosis of the jaws in Australia. $J$ Oral Maxillofac Surg 2007;65:415-23.

24. Black DM, Delmas PD, Eastell R, et al. HORIZON Pivotal Fracture Trial. Once-yearly zoledronic acid for treatment of postmenopausal osteoporosis. N Engl J Med 2007;356:1809-22.

25. Etminan M, Aminzadeh K, Matthew IR, et al. Use of oral bisphosphonates and the risk of aseptic osteonecrosis: a nested case-control study. J Rheumatol 2008;35:691-5.

26. Cartsos VM, Zhu S, Zavras Al. Bisphosphonate use and the risk of adverse jaw outcomes. J Am Dent Assoc 2008;139:23-30.

27. Morgan GJ, Davies FE, Gregory WM, et al. First-line treatment with zoledronic acid as compared with clodronic acid in multiple myeloma (MRC Myeloma IX): a randomised controlled trial. Lancet 2010;376:1989-99.

28. Aragon-Ching JB, Ning YM, Chen CC, et al. Higher incidence of Osteonecrosis of the Jaw (ONJ) in patients with metastatic castration resistant prostate cancer treated with anti-angiogenic agents. Cancer Invest 2009;27:221-6.

29. Hoff $A O$, Toth BB, Altundag $\mathrm{K}$, et al. Frequency and risk factors associated with osteonecrosis of the jaw in cancer patients treated with intravenous bisphosphonates. J Bone Miner Res 2008;23:826-36

30. Durie BG, Katz M, Crowley J. Osteonecrosis of the jaw and bisphosphonates. N Engl J Med 2005;353-99-102.

31. Bamias A, Kastritis E, Bamia C, et al. Osteonecrosis of the jaw in cancer after treatment with bisphosphonates: incidence and risk factors. J Clin Oncol 2005;23:8580-7.

32. Zervas K, Verrou E, Teleioudis Z, et al. Incidence, risk factors and management of osteonecrosis of the jaw in patients with multiple myeloma: a single-centre experience in 303 patients. $\mathrm{Br} \mathrm{J}$ Haematol 2006;134:620-3.

33. Barasch A, Cunha-Cruz J, Curro FA, et al. Risk factors for osteonecrosis of the jaws: a case-control study from the CONDOR dental PBRN. J Dent Res 2011;90:439-44.
34. Khan AA, Morrison A, Kendler DL, et al. Case-Based Review of Osteonecrosis of the Jaw (ONJ) and application of the international recommendations for management from the international task force on ONJ. J Clin Densitom 2017;20:8-24.

35. Khosla S, Burr D, Cauley J, et al. Bisphosphonate-associated osteonecrosis of the jaw: report of a task force of the American Society for Bone and Mineral Research. $J$ Bone Miner Res 2007;22:1479-91.

36. Khan AA, Morrison A, Hanley DA, et al. Diagnosis and management of osteonecrosis of the jaw: a systematic review and international consensus. J Bone Miner Res 2015:30:3-23.

37. Khan AA, Rios LP, Sándor GK, et al. Bisphosphonate-associated osteonecrosis of the jaw in Ontario: a survey of oral and maxillofacial surgeons. J Rheumatol 2011;38:1396-402.

38. Background Document for Meeting of Advisory Committee for Reproductive Health Drugs and Drug Safety and Risk Management Advisory Committee. United States. Food and Drug Administration. 2011. http://www.fda.gov/downloads/ AdvisoryCommittees/ CommitteesMeetingMaterials/drugs/ DrugSafetyandRiskManagementAdvisoryCommittee/ucm270958.pdf (Accessed 10 Feb 2014).

39. Ulmner M, Jarnbring F, Törring O. Osteonecrosis of the jaw in Sweden associated with the oral use of bisphosphonate. J Oral Maxillofac Surg 2014;72:76-82.

40. Rosen CJ. Clinical practice. Postmenopausal osteoporosis. N Engl J Med 2005;353:595-603.

41. McCloskey EV, Dunn JA, Kanis JA, et al. Long-term follow-up of a prospective, double-blind, placebo-controlled randomized trial of clodronate in multiple myeloma. Br J Haematol 2001;113:1035-43.

42. Lakatos $\mathrm{P}$, Tóth $\mathrm{E}, \mathrm{Zs} \mathrm{L}$, et al. Adherence of Hungarian postmenopausal women with osteoporosis LAM KID. 2012;2:5-15.

43. Ault A. Jaw necrosis affects 1 in 1,700 on oral bisphosphonates. Internal Medicine News 2008;41:23.

44. Hong JW, Nam W, Cha IH, et al. Oral bisphosphonate-related osteonecrosis of the jaw: the first report in Asia. Osteoporos Int 2010;21:847-53.

45. Kyrgidis A, Vahtsevanos K, Koloutsos G, et al. Bisphosphonaterelated osteonecrosis of the jaws: a case-control study of risk factors in breast cancer patients. J Clin Oncol 2008;26:4634-8.

46. Palaska PK, Cartsos V, Zavras Al. Bisphosphonates and time to osteonecrosis development. Oncologist 2009;14:1154-66.

47. Grbic JT, Landesberg R, Lin SQ, et al. Incidence of osteonecrosis of the jaw in women with postmenopausal osteoporosis in the health outcomes and reduced incidence with zoledronic acid once yearly pivotal fracture trial. J Am Dent Assoc 2008;139:32-40.

48. Wimalawansa SJ. Insight into bisphosphonate-associated osteomyelitis of the jaw: pathophysiology, mechanisms and clinical management. Expert Opin Drug Saf 2008;7:491-512.

49. Hess LM, Jeter JM, Benham-Hutchins M, et al. Factors associated with osteonecrosis of the jaw among bisphosphonate users. Am J Med 2008;121:475-83

50. Hoff AO, Toth B, Hu M, et al. Epidemiology and risk factors for osteonecrosis of the jaw in cancer patients. Ann N Y Acad Sci 2011;1218:47-54.

51. Jadu F, Lee L, Pharoah $M$, et al. A retrospective study assessing the incidence, risk factors and comorbidities of pamidronate-related necrosis of the jaws in multiple myeloma patients. Ann Oncol 2007;18:2015-9.

52. Chiu CT, Chiang WF, Chuang CY, et al. Resolution of oral bisphosphonate and steroid-related osteonecrosis of the jaw--a serial case analysis. J Oral Maxillofac Surg 2010;68:1055-63. 